\title{
Comparative Rights Jurisprudence: An Essay on Methodologies
}

\author{
Special Issue - Comparative Law
}

Ioanna Tourkochoriti*

\section{Introduction}

Paul Feyerabend's insight in Against Method (1988) that there is no single method that can produce results in scientific discourse and that all methodologies have their limits is gaining ground in the area of comparative law as well (Leckey 2017, p. 9; Adams \& Griffiths 2012; Glenn 2015; Husa 2015). In his book Feyerabend notes that evolutions in science came about just because some thinkers decided not to be bound by methodological rules or because they broke them (Feyerabend 1988, p. 14). Nevertheless, even Feyerabend, despite his prima facie radical deconstruction of the idea of a dominant method, accepts the possibility of evaluating standards of rationality and of improving them in reference to the methods we are using to obtain knowledge (Feyerabend 1988, p. 230). These reflections, are also relevant to the law, a normative discipline that has its own constraints of justifiability. This is so because legal solutions that concern the regulation of rights need to be persuasive as just. Therefore, a comparative law methodology is already preconditioned with the goal of the search for solutions that correspond to principles of justice. The methodological approach that the researcher chooses to follow needs to persuade that it does indeed serve the aim of the researcher.

This article discusses mainly three approaches that can be helpful in this area oriented in reference to three different kinds of studies that are possible in the area of comparative rights jurisprudence. It also discusses the challenges to which the researcher is exposed in her attempt to follow these methodologies. To a large extent the methods that can be helpful to a comparative legal research depend on the research question and the goal of the researcher (cf. Van Hoecke 2015, p. 1; Valcke 2012; Smits 2012; Paris 2016, p. 41). This essay proposes some methodologies for research in comparative jurisprudence understood as an effort to understand legal ideas, 'the philosophical principles, concepts, beliefs and reasoning that underlie legal rules' as applied by various jurisdictions around the world (cf. Ewald 1998, pp. 701-707, 705-706; Ewald 1995, p. 1896). It proposes methodologies for the study of the intellectual foundations of rules protecting rights in

* School of Law, NUI Galway, Ireland. 
various legal systems. Therefore, the three types of legal methodology proposed are mostly defined in reference to various goals that the researcher might aim to achieve.

First, a comparative law study may focus on the sociopolitical context that led to the elaboration of similarities or differences in the protection of rights. In this respect a study of comparative law is, by definition, an interdisciplinary study. Legal rules are a subcategory of social rules that regulate human interaction (see for instance Hart 1961). This approach aims to propose a framework for understanding the differences in the protection of human rights. The point of departure is legal hermeneutics, which points towards the conscious and unconscious factors at play in the elaboration and application of legal rules, the collaboration between mythos and logos (see Gadamer 2004, pp. 235 seq.).

Second, a comparative law approach can be a normative enterprise. It can focus on engaging in a philosophical analysis enlightened by the differences or similarities in the regulation of human rights issues, in order to propose concrete solutions for the regulation of a human right. In this approach the legal similarities or differences under comparison would provide inspiration for theoretical arguments for and against a solution in one area or another. In this approach comparative law provides a stimulus for philosophical reflection on a human right. The differences in the legal regulation of a human right can be the case study of applied legal philosophy in view of exploring a solution that seems to express principles of justice. Third, a comparative law approach can also combine both elements of the two previously mentioned approaches. It can aim at studying the sociopolitical frame that led to the emergence of legal rules and challenge them in the cases where it seems that there is some flagrant injustice in the application of rules upon concrete cases of human rights. It may aim to reach a 'reflective equilibrium' (Rawls 1972) $)^{1}$ between the is and the ought. This means that it can engage in a study that can be articulated as a back and forth movement from the differences in the operation of legal rules to how they should be operating. This will be a back and forth movement from the formation and operation of the rules in their context to a normative principle as to how they should be operating and the other way around. The study of the operation of the law in different contexts can provide insights as to how they should be operating in order to protect rights better. This can provide guidance for future cases. This back and forth movement can allow for a normative understanding of the law on rights that has real-world applications and is not construed too ideally. It can also lead to reconceptualizing (see Brand 2006-2007, pp. 405,450$)$ the current concepts upon which law regulating rights operates.

These methodologies concern studies of concrete cases of rights. They presuppose a somehow narrowly defined object of the analysis, such as studying the differences among legal systems in balancing rights in conflict with other rights or in conflict with collective considerations. Examples of the kind are hate speech,

1 Although Rawls uses the concept in moral theory to describe a way of reasoning from moral intuitions to moral principles founded on reason, I use it here in the dialectic between the is and the ought. 
where what is at stake is the need to decide the limits of freedom of expression versus reputational interests. Other cases are the regulation of wearing religious symbols, where what is at stake is the interest of the state to protect its citizens from themselves and others versus the right of the person to express herself. Some other cases can be data protection, which concerns balancing the right of the person to decide who has access to information concerning her and the rights of marketeers to have access to data. Other case studies may concern conflicts that emerge around the enforcement of anti-discrimination law. The last category gives grounds for study in reference to the preference for the protection of one type of freedoms through anti-discrimination law such as freedom of religion to the detriment of other types such as welfare rights. The right not to be discriminated against often collides with the right to freedom of religion. The need to protect the autonomy of religious institutions has led some legal orders to accept exemptions in the enforcement of anti-discrimination law when religious institutions put forth that they need to discriminate out of respect for their religious convictions.

The article discusses the challenges that the researcher faces in her attempt to use these methodologies and how these challenges can be overcome. First, these challenges arise in the selection of cases that are appropriate for comparison, in assuring comparability. What is at stake is the question of commensurability. If what motivates a comparative law study is the search for principles of justice the researcher needs to persuade that her methodological approach serves her aim and that the cases she has chosen to study are comparable. Second, challenges emerge for the comparatist concerning the research question that she uses, her theoretical framework and her criteria of evaluation. Furthermore, these challenges concern the validity of the interpretative schemata that she refers to or that she creates in order to interpret the legal phenomena she is studying. These interpretative schemata may be defined by conscious and unconscious bias. Although to some extent it is impossible for the researcher to transcend the subjectivity of her perspective, there is a moral obligation for the researcher to make an effort to transcend this bias. Interdisciplinary collaboration as well as collaboration with scholars whose background was formed in the foreign legal system under study can help transcend these challenges. Another concern for the comparativist is the danger of being trapped in the relativity of her background, which would prevent her from thinking critically about the object of her study. The solution to the problem comes from the reflection on the just character of the rules that is implicit in any attempt to compare legal rules. The inherent normative dimension of the law can help transcend the circumstances that define the biases of the researcher. The law as a normative discipline has its own constraints of justifiability. The researcher is led to transcend her conditioning in a context that provides to her a frame of evaluation and to think in abstracto about principles of justice. The comparatist who studies legal rules inevitably transcends her horizon and is led to think about the justness of the legal rules she is studying. 


\section{Theoretical Framework}

I use here the term 'right' in the Hohfeldian sense, as an interest protected by a legal order, which is correlative with others' duty to respect it. As such, rights imply concrete obligations by the state (Newcomb Hohfeld 1964, p. 33). Different jurisdictions may follow different conceptions on the extent of the positive obligations of the state to respect a liberty and enforce its protection by others within civil society. Different states may follow different conceptions in converting liberties, always in the Hohfeldian sense, into rights. Studying legal rules that regulate rights from a comparative perspective is an area of research where there is a continuum between various social and theoretical sciences. ${ }^{2}$ If Foucault is right in noting that 'disciplinary' discourse exercises power upon its object by dividing an area of knowledge and limiting the possibilities of scholars to see things otherwise (Foucault 2010, p. 49; Foucault 1977, pp. 211, 222, 226), then comparative law is the area of research that can liberate the mind rebelling against these rigid 'disciplinary' distinctions that 'discipline' the mind. Comparative law scholars have noted the interdisciplinary character of comparative law as an approach to the study of the law (Grosswald Curran 1998; Husa 2014). Nevertheless, some scholars note the unfulfilled potential for meaningful connections between other disciplines such as legal sociology and comparative law and recommend that communication and comparison require 'thick descriptions' to be meaningful (see Cotterrell 2016, pp. 127, 141). Few comparative studies offer this interdisciplinary perspective that studies cases from an interdisciplinary perspective and that lead to meaningful insights. The methodologies proposed in this article also are based on this insight recommending various disciplinary angles for comparative analyses of rights jurisprudence.

The methodologies analysed below presuppose a conception of a legal system as jurisprudence, composed of factual as well as ideational, normative elements, and as such these methodologies can help explore how various juridical ideas protected as rights have materialized in different polities (see Valcke 2004, p. 739). Comparing legal rules involves identifying some similarities, for the case of a right that is important to protect. It also involves attempting to identify units of variation that are worth studying (see McCrudden 2017). For a comparison in the area of human rights it is the substantive rulings that are important that have found legal form in legal texts and legal decisions and less the legal form in which they have become positive rights.

2 Mark Tushnet notes that in the area of comparative law 'The boundary between law and other academic disciplines has become blurred', Tushnet 2017, p. 17. 


\section{The Three Methodological Approaches}

\subsection{Sociopolitical Context}

One approach could be to engage in a study of the historical and sociopolitical context that motivated different constitutional systems and legal orders to regulate the exercise of a liberty in one way or another. For instance, a comparative study of the permissibility of regulating the wearing of headscarves in public places implies studying the historical and sociopolitical context that makes regulating individuals' dress choices legitimate in one legal system and illegitimate in another (see, for instance, Tourkochoriti 2012). A comparative law study may focus on the sociopolitical context that led to the elaboration of differences in the legal regulation of human rights questions. Legal rules are a subcategory of social rules that regulate human interaction. Engagement with social theory can provide insights into the social origins of legal rules. I am deliberately avoiding the term 'culture' at this point as it is too vague. ${ }^{3}$ This approach aims to propose a framework for understanding the differences in the protection of human rights. It may also propose to reflect critically on this framework.

The question is relevant with reference to the scope of the protection of human rights, for instance in cases of exploring their limits that courts decide to trace on the balance with other legal rights and social considerations. The point of departure here is legal hermeneutics. This methodological approach points towards interpreting the conscious and unconscious factors at play in the elaboration and application of legal rules. Hans-Georg Gadamer notes in his capital book Truth and Method that there is always a collaboration between mythos and logos (see Gadamer 2004) whenever an interpreter is making sense of a text. This distinction aims to underline that part of the elements at play in legal reasoning come from biases and prejudices conscious and unconscious and part of them come from the use of reason. The reasoning of jurists when they debate whether it is legitimate for the state to limit a right or not is influenced by factors that they can control, their reason, logos, and factors that they cannot control, all sorts of prejudices, mythos. The comparatist will thus aim to propose an interpretation of some elements that compose the mythos and the logos of the jurists in a legal system when they discuss the permissibility of limiting a right.

For instance, an analysis of the differences in the regulation of headscarf bans can focus on the dominant understanding of the role of the government in various constitutional orders (see Tourkochoriti 2012). This would imply studying to what extent it is legitimate for the government to intervene and define the dress choices of the citizens, to protect them from themselves and social pressure in their dress decisions. An understanding of the role of the government presupposes the study of theories on its mission and how these theories have been understood and applied in various constitutional orders. Very often, referring to the political debates that elaborated the framework of a constitutional order can

3 The idea of 'legal culture' has been criticized by many comparatists as being very vague and difficult to define as such. See Nelken 2016; Riles 2006; Cotterrell 2006, p. 140. 
be helpful, always taking into consideration that these ideas evolve through time as societies evolve. The divide in harsh punishment between various systems in the world can be studied in reference to the general socio-political context, which leads to a variability in the understanding of the role of criminal punishment (see Whitman 2003). A study of the right to privacy can lead to insights concerning the entity mostly feared as likely to violate this right in different legal contexts, civil society actors or the state (Whitman 2004; 2005, p. 98 seq). A study of how anti-discrimination law operates within various legal systems can lead to conclusions on which liberties are more worthy of protection in various legal systems (Suk 2007b; 2007a; Tourkochoriti 2015; 2017). A study of hate speech in Germany can enlighten the constitutional culture of that country as one that accepts limitations to free speech, in opposition to the US, where the self-understanding points towards protecting free speech (see Tushnet 1998-1999, p. 1278). ${ }^{4}$

This approach is a version of the one comparativists have characterized as the search for 'mentalités' (Samuel 1998; Legrand 1995, p. 273) and 'Styles of thought' (Ewald 1994-1995, p. 1948). It is also close to what some other scholars have characterized as 'expressivism', the inquiry as to how constitutions help constitute the nations, 'offering to each nation's people a way of understanding themselves as political beings' ${ }^{5}$ It is also broader than this as it aims at identifying wider patterns of thought and ex ante understandings, conscious and unconscious elements at play within the understandings of jurists on the legitimate limits of a liberty within a legal system. It aims at discovering the ideological underpinnings that lead to 'mentalités' and styles of thought. It aims at pointing out, for instance, why judges interpreting legal clauses that seem to be close linguistically are led to divergent results in the protection of a right. For instance, it can help understand why judges and other jurists using tools in their reasoning such as balancing or proportionality, which have become the new 'lingua franca' around the world (Bomhoff 2008, p. 570), are led to different results in different parts of the world. Some elements of the philosophy of history are intertwined with this approach to the extent that a reflection on the philosophical meaning of historical events would make sense from a comparative point of view in reference to some broader philosophical ideas. A comparative study that focuses on the historical context will need to discuss how different jurists, that is legal scholars, judges, legislators and the like make sense of philosophical principles and how they use the law to implement them. This approach inevitably implies a study of the dialectic between the is and the ought and how jurists make sense of this dialectic and implement it through the law. This is Hegel's approach to the philosophy of history, seeing history as the realm of the interplay between the is and the ought (Hegel 1991). ${ }^{6}$ Hegel associates this vision with how human actors are trying to transform their reality while they are limited by what is realizable depending on

4 For an extended analysis of free speech from this perspective, see Whitman 2000, pp. 12791398.

$5 \quad$ For this definition see Tushnet 1998-1999, p. 1228.

6 For instance, for his analysis of the French Revolution see p. 450 seq. 
the level of the maturity of reason within their societies. Even if we do not follow Hegel's conception of a progressive realization of reason in history, it is always helpful to examine how different political problems can be resolved in reference to different principles that find consecration and embodiment through the law. In the area of rights this approach would imply studying various theories of government and seeing how different political and legal actors made sense of them in order to respond to their varied sociopolitical needs. If we accept that there is a dialectic between the is and the ought, the understanding of legal actors of these theories is conditioned by the sociopolitical needs with which they are confronted. At the same time the guidance of a principle motivates the ambition to change reality in these political and legal actors. At a third level the researcher can refer to these abstract ideas and criticize the efforts of political and legal actors to implement them. Therefore, an effective comparative study in the area of human rights needs to focus on the study of various sociopolitical contexts and the problems they create, the reactions of legal and political actors to them and the principles that motivate the reaction of these actors. This interdisciplinary study on all these levels, the level of reality, the level of normative principles and the way various actors make sense of these principles in order to respond to these sociopolitical problems aims to propose a wider interpretative frame that can help understand the differences in the regulation of rights and liberties in various constitutional orders.

For instance, studying the most important philosophical ideas on the role of the government at the moment of the French and the American Revolutions can elucidate why it is legitimate for the state in France to regulate the wearing of headscarves in public. The choice of a theory of government at the moment of founding a republic is dictated by concrete political and social needs. In France during the French Revolution the mission of the government was seen as ensuring that the citizens would have the necessary preconditions for the exercise of their liberties. It was also seen as necessary to exclude religion from the public sphere. Jurists in France today understand this principle to mean that the government can regulate the extent to which citizens are allowed to wear headscarves in public. The prohibition on covering one's face in public can be understood as part of a wider conception of top to bottom secularism that dictates to individuals that they should not manifest conspicuously their religious convictions. ${ }^{7}$ The French legislation on secularism can be understood as part of this wider perspective of state-imposed secularism that expresses disregard for individual reason. The state helps individuals realize their liberty as they cannot realize it by themselves. The state can intervene and make sure that they are authentically free. It also means that the government is allowed to repress manifestation of religion in public. Understanding these reasons as being at the origin of regulation of wearing headscarves in public can lead to a philosophical reflection as to their permissibility today. If the understanding on the role of the government elaborated during the French

7 For an analysis of the ban on wearing conspicuous signs of religious affiliation in France, dictated by conception of secularism from the top to the bottom, see Tourkochoriti 2012. 
Revolution aimed at responding to concrete social and political needs, today these social and political needs may have changed. Thus, these changes may necessitate a change in the theory of government in France. It may no longer be permissible for the state to dictate to the citizens that they should not manifest their religious beliefs in public. Doing so may lead to a number of unintended consequences that do not allow peaceful coexistence between religious groups.

\subsection{A Normative Enterprise}

Second, a comparative law approach can be a normative enterprise. It can focus on engaging in a philosophical analysis enlightened by the differences in the regulation of rights, in order to propose concrete solutions for the regulation of a right. In this approach the study of differences or similarities between different legal orders in the balancing of rights can provide stimuli for philosophical reflection on a right. In this approach the legal approaches under comparison would provide theoretical arguments for and against a solution in one area or another. ${ }^{8}$ For instance, studying the differences in the regulation of hate speech between the USA and European countries can lead to a philosophical reflection on the permissibility of hate speech. It can engage with exploring whether the American or the European solution to the problem corresponds better with principles of justice. Hate speech leads to conflicts of rights between the person who expresses herself and the persons whom she offends with her hate speech. Which solution concerning the balancing of rights in conflict or the balancing of individual rights and collective considerations should be preferred? Different solutions to this question are motivated by different principles considered important. A philosophical analysis of the permissibility or not of the exercise of a right can be enlightened upon the rationales that jurists use in different constitutional systems to limit rights and liberties. The differences in the legal regulation of a human right can be the case study of applied legal philosophy in view of exploring a solution that seems to express principles of justice. This approach on the normative level aims to identify principles that compose the ought, how societies should devise norms to regulate human rights issues. It is concerned with elaborating a theory of rights that can be enlightened by how and to what extent various legal systems protect these rights.

For instance, studying how different countries regulate hate speech can be the basis for a philosophical reflection on the legitimate limits of free speech (see Tourkochoriti 2014a). Different legal orders have different legal evaluations of what harm is, and this can lead them to different conceptions of regulating speech, which may involve criminal sanctions, civil responsibility or even absence of stricto sensu legal consequences allowing social sanctions the room occupied elsewhere by legal sanctions. For instance, the US legal system seems to be more reluctant than that of the European states to limit hate speech through the use of civil or criminal sanctions. Nevertheless, there are social restrictions against hate 
speech in the US. The practice of political correctness leads to the social isolation of those who express hateful ideas. These differences in the evaluation of social harm can stir a valuable philosophical reflection on the legitimate sphere of government action. Should it intervene in order to enforce the protection of citizens against offences caused by speech, as is the case in most European states today, or should it allow society to regulate cases such as this through other mechanisms such as social sanctions, as is arguably mostly the case in the US. Furthermore, a comparative study of hate speech that follows this methodological approach can help refine further the crucial legal concepts. In this case, it can help reflect on the concept of hate speech itself towards a theoretical understanding of what should be understood as hate speech. This theoretical understanding will model in itself how lawyers should understand these concepts in future cases that come up, allowing them to have a more sophisticated approach to these issues.

Courts around the world use various techniques to evaluate the importance of limiting or protecting rights. As J. Bomhoff has noted, very often they even refer to the same technique such as 'balancing', which is used differently in different contexts. Courts use balancing either to accept as legitimate the exercise of political authority in limiting the exercise of these rights or to achieve the opposite result, which is to limit the authority of the state in its efforts to limit rights (Bomhoff 2008, p. 559). Courts refer to notions of fairness and rationality that are presented as having a universal dimension, while they are merely reflecting local understandings created on the basis of sociopolitical factors (Ibid.). A comparative study can explore arguments for or against each of these practices. It can thus contribute towards a philosophical exploration of government legitimacy in its efforts to limit rights. Studying cases where there seems to be agreement across jurisdictions on the appropriate limits of a right can stir a philosophical reflection on whether a right has and should have a universal character or not. ${ }^{9}$

This approach is beyond what is commonly understood in the area of comparative law methodology as functionalism. Functionalism aims at pointing out the role that constitutional arrangements play in a system of governance in order to identify how different constitutional provisions serve the same function in different systems. ${ }^{10}$ Functionalism is mostly a descriptive approach, whereas the approach proposed here is normative. The methodology proposed here aims at encouraging a theoretical reflection on how functions should be served within a constitutional system. Functionalism has been criticized as running the risk of encountering two difficulties. ${ }^{11}$ First, functionalist approaches may omit some relevant variables in their effort to study common grounds among legal systems. This means that the way the law works in different legal systems is too intricate and the possibilities of any individual researcher are limited in her efforts to describe them.

9 In this respect, this methodological approach lies beyond the debates on whether comparative law scholarship should focus on similarities or differences. Both can be equally helpful in stirring a theoretical reflection on the need to protect a right, and under what circumstances limits to the protection of this right may be accepted. See Dannemann 2006.

10 For this definition of functionalism, see Tushnet 1998-1999, p. 1228.

11 Ibid., p. 1265. 
In the case of hate speech this would mean that the case law of the courts is too sophisticated and too intricate for a comparatist to describe it accurately across legal systems. Second, even when a limited number of additional variables are taken into account the number of cases that may be of interest turns out to be too small to support any functionalist generalization. In the case of hate speech this may mean that it is difficult to say whether legal systems agree in the regulation of all cases of hate speech or not. The methodology proposed here is insulated from these criticisms as the study of the existing state of the law is merely the point of departure of a theoretical reflection on what the law should be. As a study of jurisprudence and not merely a study of positive law, minor deviations and nuances might actually be helpful as offering interesting arguments for a philosophical reflection.

Furthermore, unlike functionalism, this approach concerns not only similarities but also differences in the regulation of human rights. In many cases this approach can provide a theoretical reflection towards resolving cases of conflict of laws that are very relevant from a transnational perspective. For instance, the differences in data protection recently noted between the European Union and the USA (Schwartz 2013, pp. 1966, 1979: Schwartz \& Solove 2014; Tourkochoriti 2014b) can stir a philosophical reflection on these issues that can be inspired by arguments used for and against regulation of data collection by public and private entities. Data collectors can be either the state or private market actors. Different legal systems may protect more strictly data privacy against collection coming from private actors than against the state. The comparatist may engage in a reflection on whether there are different dangers in the collection of data between the state and private actors and recommend solutions in both cases.

Since the study of law is, by definition, the study of norms that regulate human behaviour and interaction, comparative law helps with this approach elaborate legal rules that can help towards problem solving in the area of protecting rights. It can lead to greater sophistication in the understanding of the legal concepts that jurists use. ${ }^{12}$ It can provide insights that can be helpful to the legal argumentation of all jurists as they interpret and apply even existing legal rules within their legal system of origin. This approach can thus be helpful to lawyers in their effort to bridge the general abstract legal rules and the concrete facts to which they attempt to apply them. Once these abstract criteria of how they should understand their concepts are defined as a result of this comparison, they can then form and model how these lawyers think in their own tradition, given that there is a dialectic between how lawyers apply the law and how they will think that they should apply the law once the comparative study has been completed.

\subsection{A Combination of Both These Approaches}

Third, a comparative law approach can combine both elements of the two previously mentioned approaches. First, it can aim to study the sociopolitical frame 
that led to the emergence of legal rules and challenge them in the cases where it seems that there is some flagrant injustice in the application of rules upon concrete cases of human rights. Second, it may incite a philosophical reflection on the proper regulation of a right. For instance, studying anti-discrimination law in the access to employment in the USA and European countries can lead to finding differences and similarities in the mission and the goals of anti-discrimination law. These differences and similarities can encourage a reflection on how anti-discrimination law can be more effective. It can also lead to a better understanding of the crucial concepts that anti-discrimination law uses. And it can lead to proposing new concepts that may be more useful towards eliminating discrimination. This means that this approach can lead to a reconceptualization of the various legal tools that jurists use in Europe and the US in order to combat discrimination in the access to employment.

This approach, shares with the first approach discussed in Section 3.1, that it is an interdisciplinary study. It aims at proposing a theoretical framework for understanding similarities and differences in the protection of rights among various legal orders. This framework will also help evaluate the existing regulations. A study of this kind focuses on the existing legal structure as well as the theoretical basis upon which it rests. Interdisciplinarity in this area means engaging with research in the social sciences, which can help understand the political and social purposes of legal rules. In this sense a comparative study aims to show overall how problems that have emerged in one jurisdiction are addressed in another (Glendon et al. 2007. It aims to reach a 'deepened understanding' of a social and political problem, which can be the source of inspiration for providing better solutions. This approach aims at highlighting the different sensibilities concerning pressing concerns on rights and at evaluating them. Comparative law entails an interdisciplinary approach and a focus on context, the structural and contextual background to the rules under comparison (Palmer 1998). ${ }^{13}$ The study will focus on the structure of the relevant concepts, their emergence and philosophical underpinnings.

Further, this approach uses the second approach, discussed in Section 3.2, of encouraging the researcher to engage in a normative reflection on the similarities or differences in the regulation of rights. This approach may aim at reaching a 'reflective equilibrium' (Rawls 1973, p. 20) ${ }^{14}$ between how the law works and how it should be working. This means that it can engage in a study that can be articulated as a back and forth movement from the differences in the operation of legal rules to how they should be operating. This will be a back and forth movement from the formation and operation of the rules in their context to a normative principle as to how they should be operating and the other way around. The study of the operation of the law in different contexts can provide insights as to how

13 For a focus on cultural immersion as a prerequisite for effective comparative analysis, see also Grosswald Curran 1998.

14 Although Rawls uses the concept in moral theory to describe a way of reasoning from moral intuitions to moral principles founded on reason, I use it here in the dialectic between the is and the ought. 
they should be operating in order to protect rights better. This can provide guidance for future cases. This back and forth movement can allow for a normative understanding of human rights law that has real-world applications and is not construed too ideally. It can also lead to reconceptualizing (see Brand 2006-2007, p. 450) the current concepts upon which human rights law operates. In this case the aims of the study are to challenge the existing philosophical and sociopolitical frames that lead to legal differences in reference to new case studies in order to propose changes in the way of thinking of various legal and political actors.

For instance, a study against discrimination in the access to employment in the U.S. and the EU can have as its aim the study of the existing legal rules and how they operate. A study of comparative anti-discrimination law can aim to highlight the different sensibilities of anti-discrimination law in the US and the EU and to evaluate them. Understanding the philosophy inspiring the legal rules will help evaluate the exceptions to the rules against discrimination. For instance, the primacy given to freedom of religion in the US, owing to concrete philosophical, historical and social reasons, may lead to interpreting the exceptions to the rules against discrimination in a way that makes anti-discrimination law meaningless. The US Supreme Court has accepted that under the rule of the ministerial exception, religious institutions can be exempt from the application of disability anti-discrimination law. ${ }^{15}$ The study of the sociopolitical context that led a legal system to giving priority to protecting one category of rights will lead the researcher to a deeper understanding of why the US gives priority to protecting some rights to the detriment of others. It may also incite a normative reflection as to whether the ideology that inspired this state of the law is just and still relevant today. For instance, in the case of balancing religious autonomy versus enforcing disability anti-discrimination law, the need to protect minority religious communities, which was compelling during the founding era in the US, may have to cede to the compelling need to protect other social groups today such as the disabled. ${ }^{16}$ A similar argument can be made once the researcher has engaged in a normative enterprise on the importance of enforcing disability anti-discrimination law. For the study of anti-discrimination law the study of the cultural values that lead to discrimination is very important in view of addressing solutions. In parallel, research on discrimination from a social and political theory perspective can enlighten further the importance of legal intervention in concrete areas.

Situating the rules of anti-discrimination law in the social and political context that has produced them can help criticize these rules in view of improving them with the aim of promoting social change. The comparison of how the rules are working in practice will allow the researcher to develop criteria for how they should be operating. The idea of 'reflective equilibrium' discussed by John Rawls (1972) describes the process that the researcher can follow in this respect. Although Rawls uses the concept in moral theory to describe a way of reasoning from moral intuitions to moral principles founded on reason, I use it here in the 
dialectic between the is and the ought. In this context it means a back and forth movement from the operation of legal rules to how they should be operating. The study of the operation of human rights law in various legal contexts will provide insights into how they should be operating and serve as a basis for guidance in future cases. This will be a back and forth movement from the formation and operation of the rules in their context to the principle and the other way around. This back-and forth movement can allow for a normative understanding of rights protection that has real-world applications. It can also lead to reconceptualizing (see Brand 2006-2007, pp. 405, 450) the current concepts upon which the law operates. As Geoffrey Samuel notes, this approach is simultaneously based on a deconstruction of the current understandings of legal concepts and reconstruction of doctrinal analysis concerning how rules should be understood and applied in concrete legal cases (Samuel 1998, pp. 835-836). As such, this approach can make a significant contribution to jurisprudence.

For instance, in the case of anti-discrimination law, the American legal system protects more strictly against discrimination in the exercise of negative liberties such as freedom of religion. European states protect less against discrimination in the exercise of negative freedoms and more against discrimination in positive freedoms (Suk 2007b; Tourkochoriti 2015; 2017). This indicates the different sensibilities in the US and the EU and the different theories of government that are dominant in these two legal systems. In the US it is legitimate for the state to intervene in order to protect negative liberties. In Europe the state intervenes in order to protect positive liberties as well. Is there something wrong with giving the priority to a set of anti-discrimination claims to the detriment of another set? The researcher can engage in a theoretical reflection on these questions in reference to the real-life applications of anti-discrimination law.

The three methodological approaches analysed in this part, an approach that focuses on the sociopolitical context, a normative approach and a combination of the two, indicate that comparative law is a challenging enterprise. It is challenging because of its interdisciplinary character and also because it is a very ambitious enterprise, involving transcending the researcher's comfort zone. It implies studying legal rules in different social and political contexts from the researcher's own legal system. It also implies expanding the horizons of one's knowledge in the area of neighbouring disciplines, which can be extremely demanding. In the second part that follows, I analyse these challenges and argue that it is possible to overcome them.

\section{Challenges}

The challenges involved in engaging in interdisciplinary research are significant. Nevertheless, they are not insurmountable. The very nature of legal comparison can help the researcher transcend the challenges she is confronted with. First, challenges arise in choosing the cases that are appropriate for comparison. The researcher needs to persuade persuade that there is commensurability in the cases she is studying that allow her to make conclusions about the relevant legal 
phenomena. A second challenge lies in the fact that the research question that the researcher uses, her theoretical framework and the evaluating criteria will be conditioned from her point of view. Her situation in a context of meaning also affects the validity of the interpretative schemata that she creates in order to interpret the concrete legal phenomena she is studying. The researcher will need to refer to theoretical frameworks that have already been elaborated by others, and to some extent she will need to use them or criticize them in reference to her own purposes. To some extent it is impossible for the researcher to escape the subjectivity of her perspective as her perspective is often defined by unconscious prejudices that she cannot always dispose of. Nevertheless, there is a moral obligation for the researcher to be open to the 'newness' of the materials she is studying and to try to reflect critically upon her prejudices. Collaborating with researchers having other disciplinary backgrounds and jurists operating in the new legal culture that the researcher is studying is also extremely important. Another concern for the comparativist is the danger of getting trapped in the social relativity of the legal tradition that has formed her background, which would prevent her from reflecting critically on the object of her study. This would make it difficult to reach a reflective equilibrium between how the law operates and how the law should operate. This challenge can be overcome if we consider that the law is a normative discipline. It studies the ought. The researcher is studying rules, which implies that she is inevitably asked to take a position on the justness of these rules. When analysing a normative subject it is impossible to avoid taking a position. As Jürgen Habermas notes, ${ }^{17}$ the researcher is led to transcend her conditioning in a context that provides to her the frame of evaluating and to think in abstracto about principles of justice. The comparatist engages in her study in order to transcend her horizon and to think about the justness of the law. In this effort, transcending the situation of her context is inevitable.

First, challenges arise in choosing the cases that are appropriate for comparison, in assuring comparability (Hirschl 2005). In other words, what is a stake here is the question of commensurability. The comparatist must be careful in the selection of her cases and of the interpretative scheme that she uses to approach them. Gabriel Tarde noted that the narrower the focus of the social scientist who is studying a phenomenon, the greater the singularity of the phenomenon appears, thus making its comparison with others difficult (Tarde 1893, pp. 157-175, 231246. See also Matagrin 1910, p. 31). Durkheim elaborated his theory of 'emerging properties' in response to Tarde in order to underline the possibility of addressing collective characteristics of groups of persons that can be attributed to them at a macro level. According to this theory, when individuals are brought together as part of a group, new properties emerge that can be used to characterize them. These properties differ from their properties seen as individuals. This conception is thus enabling commensurability. For instance, Durkheim's description of the idea of 'collective consciousness' can be an element of commensurability to the extent that it denotes the rational and irrational elements that hold a society 
together (Durkheim 1984, pp. 226 seq). This gap between the narrow focus, which may create problems for commensurability, and the macro focus, which allows more easily for commensurability, has to be filled in by the comparatist who needs to persuade for the validity of her case selection and the schema that she is using to interpret it. For instance, in the comparison of the responses of France and the US to hate speech, too narrow a focus on concrete cases might present, at first sight, the impression that the cases the comparatist is using are incommensurable as detailed facts may differ across jurisdictions. By enlarging the focus, however, the researcher may be able to detect a 'collective consciousness' in the US that points towards a greater sphere of permissibility of hate speech, as opposed to a 'collective consciousness' in favour of limitations in France. ${ }^{18}$

Feyerabend's insight that approximations play a very important role in the positive sciences (Feyerabend 1988, p. 49) is very important for the task of the comparativist. Comparative law is to a great extent based on ad hoc approximations, which allow for commensurability. As Feyerabend notes, in some circumstances defending ad hoc hypotheses or hypotheses that contradict established results is the best way to increase knowledge (Feyerabend 1988, pp. 14-15). Transposed to the area of law, this means that the researcher is free to choose the cases she considers worthy of studying and should try to be innovative in her approach as only this creativity can promote knowledge and reflection on the justice of our rules. Nevertheless, she needs to propose and justify why she thinks there is commensurability in the cases she is studying. For instance, comparing the attitudes of the US and France towards free speech makes for a good case of comparison if the researcher provides as a justification that these countries, although sharing the same background of the Enlightenment, react differently towards a right that is at the heart of the Enlightenment, the right to freedom of expression. The researcher also has the possibility to modify her research question in a way that makes for a better commensurability (Valcke \& Grellette 2015).$^{19}$ In the wider area of free speech issues she needs to choose cases that allow for commensurability, and she needs to justify why this is the case. If the comparatist decides to compare cases of rights that do not fit the same background ideology as the aforementioned example of free speech, then she will have to explain why it makes sense to engage in this comparison of these elements and propose the points of commensurability she considers are important (see Tourkochoriti manuscript).

Second, challenges emerge for the comparatist concerning the choice of the research question, the theoretical framework and the evaluating criteria that the researcher uses. In other words, the validity of the interpretative schemata that she refers to or creates herself in order to interpret the legal phenomena she is studying is conditioned by her perspective. For instance, an attempt to compare the understanding of socio-economic rights in different jurisdictions presupposes

18 On this point see Tourkochoriti Freedom of Speech (manuscript).

19 Husa 2015 defines the method of comparative law as a process articulated in several phases, characterized frequently by setbacks, at p. 54. The researcher has the possibility to redefine her research question during a process in a way that approximates commensurability. 
an effort to reconstruct the socio-economic origins of legal rules. This effort poses some challenges that concern the possibility to take all the relevant factors into consideration. As Clifford Geertz has noted, the law is a system of meaning in a dialectic relation with social context: it constitutes social relations and is constituted by them (Geertz 2010, pp. 182, 184, 230; see also Mautner 2011). Geertz warns against a challenge that emerges in any comparative approach: 'to formulate the presuppositions, the preoccupations, and the frames of action characteristic of one sort of legal sensibility in terms of those characteristic of another' (Geertz 1983, p. 218). ${ }^{20}$ The danger exists that since the study will aim to reflect on the justness of concrete human rights rules, the sensibilities and the evaluating criteria will be conditioned from the researchers' point of view. This conditioning affects the very framing of the research question, the interpretative schemes as well as the conclusions of the researcher. For instance, a researcher who aims to engage in a comparison of how anti-discrimination law operates in the US and the EU has already an understanding of some important legal concepts that is formed in the context where she received her legal education. The same study presupposes that the researcher has an understanding of anti-discrimination law that is formed within a legal context and its own sociopolitical origins. Her research question, the case studies of anti-discrimination law that she considers important and commensurable, will be defined by her ex ante understanding of all these concepts, which is formed in a concrete social and political context. The interpretative scheme that she will use to approach her topic and her conclusions will very likely be conditioned by her formation and her circumstances. A study on socio-economic rights presupposes an understanding and definition of what counts as a 'socio-economic right', which is formed in a context of meaning.

To some extent the fact that the researcher's questions, interpretative schemata and conclusions will be conditioned by her situation in a context of formation and meaning is inevitable. Since thinkers such as Wilhelm Dilthey, Edmund Husserl and Martin Heidegger pointed towards the verstehen approach as a basic feature of human existence, this approach gained ground as the appropriate way of making sense of social phenomena in the social sciences. This approach presupposes recognition of the subjectivity of the researcher in making sense of social reality. Max Weber has insisted on the need for researchers to isolate their world views in their approach of their topic (Weber 2003, p. 374). Ideally, for Weber the researcher should be able to distinguish between her belief in the validity of the values she espouses and the object of her study (Ibid., pp. 362-363). Weber recognizes the difficulties inherent in any such enterprise and nevertheless makes a distinction between 'value judgments', which concern the validity of ethical norms that motivate our beliefs, and 'experiential knowledge', the need for 'conceptually ordering empirical reality in such a manner as to lay claim to validity rules institutions in other societies happens at the background of the researcher's legal system and doctrinal framework, at p. 27. Pierre Legrand 1999 also notes the 'cultural' unconscious elements that may be perspectival obstacles to understanding another legal mentality. 
as experiential truth (Ibid, p. 365). Weber notes that this does not mean that cultural scientific research can have results that are valid only for one person and not for another. The investigator is bound to the norms of thought. Weber seems to believe that it is possible for the social sciences to organize their material as a system of concepts that can be perfected through the observation of empirical regularities.

This approach has been the object of criticism. Jürgen Habermas has noted that concept formation presupposes familiarity with language. This means that the researcher always has an ex ante understanding formed on the basis of a pre-theoretical knowledge of terms and concepts (Habermas 1981, p. 110). Furthermore, Habermas has noted that understanding in the social sciences has a communicative and performative dimension to the extent that it presupposes an engagement with values in the very formation of a concept and with how other human beings understand values (Ibid., p. 113). For instance, a researcher cannot make sense of the meaning of a right unless she interacts with the legal actors and authors who make sense of what a right is in contexts of social action. This implies that the researcher must consider the reasons that legal actors can have in various contexts for accepting the validity claims for a right, and they are themselves drawn into the process of assessing these validity claims (Ibid., p. 115).

Weber himself understands that in the area of evaluation of legislation the distinction between value judgments and experiential knowledge is impossible. A critique of legislation implies 'confrontation of value standards with others and ideally with one's own'. And Weber recognizes that the concept of culture is an evaluative concept presupposing the choice of a particular perspective (Weber 2003, p. 377). The construction of our concepts depends on the posing of the problems. In this respect any cultural scientific knowledge cannot escape some presuppositions that are made by the researcher. In the area of comparative law concerning human rights issues the difficulties are even greater. In the area of the normative science that is the law, the difficulties in adopting this 'objective' point of view become more obvious. Questions of balancing rights involve a judgment of value, a commitment to a perspective in favour of some greater or lesser degree of protection of a right. The very definition of what constitutes a right presupposes a position and a situated understanding formed in a social context through communicative experience with others. This is all the more obvious in the case of socio-economic rights, given that there is significant disagreement all around the world about what should count as a socio-economic right.

Hans-Georg Gadamer has noted that the researcher's understanding of concepts and values is defined by her situation in a context of formation (Gadamer 2004, p. 235). This context conditions the ideas of the researcher. The researcher, in her effort to make sense of a text or a social phenomenon, carries in herself prejudices some of which are conscious and some unconscious. To some extent, it is impossible to the legal researcher, as social scientist, to dissipate the unconscious prejudices in her effort to make sense of a new legal culture (Ibid.; see also Legrand 2011; 1995, p. 266). Nevertheless, even Gadamer seems to point towards a moral obligation for openness on the part of the social scientist. Gadamer discusses Martin Heidegger's analysis of the hermeneutical circle (Heidegger 1962, p. 153). 
According to the metaphor of the circle, the process of understanding follows a circular movement in which the interpreter of a text initially projects some of her own ex ante understandings of the text in the meaning of the text. As the reading of the text progresses, the interpreter verifies her own ex ante understandings and preconceptions on the meaning of the text in reference to the newness of the text. For the comparatist as a social scientist, this means that she should be open to the newness of the material that she is studying. The legal researcher conducting a study in comparative law as a social scientist is conditioned by her circumstances, her weltanschauung and her conception of justice in her attempt to make sense of the legal rules in various contexts (cf. Gadamer 2004, p. 238). This is especially so for the comparativist whose understanding of the legal rules worthy of comparison is already conditioned by her situation in a legal culture. To some extent her interpretations will be conditioned and biased. Nevertheless, there is a standing moral obligation on behalf of the researcher to try to moderate her own prejudices and biases to the extent that this is possible. Arguably, moderation is the first maxim of virtue ethics. ${ }^{21}$ The comparatist should be motivated primarily by respect of the collective experience consecrated through law that she studies, given that the law is much more than a facilitator of transactions (see Cotterrell 2006, p. 734), especially so in the area of rights. Furthermore, collaboration among researchers and openness to a wide variety of research materials globally can help moderate the impact of the researcher's preconceptions on her work. The researcher will need to remain in close communication with legal actors and social scientists operating in the legal culture she is studying. Teamwork between scholars from different disciplines (cf. Husa 2014) as well as between scholars from the various legal and sociopolitical contexts studied will contribute to eliminating biases that come from a researcher's methodological and sociopolitical background.

Another concern that scholars have noted with approaches (a) and (c) proposed in this article is that following them might lead to getting entrapped in the social relativity of the various legal traditions under consideration, which means that the researcher becomes unable to engage in a reflective equilibrium between how various legal systems protect a right and how this right should be protected. ${ }^{22}$ Following this methodology thus means reducing law to the social and geographical relativity of ideology and negating the possibility of a theoretical reflection on the law. It would also mean that comparative law would be just a methodology that cannot necessarily provide any helpful reflections about what is the law. ${ }^{23}$ In other words, comparative law needs a methodology, which promotes knowledge of the law as a normative science.

Habermas's analysis of the methodology of the social scientist as a communicative practice can help respond to this concern that comparatists may have as well.

See Michael Frazer, 'The Ethics of Causal and Interpretive Social Explanations', Paper presented at the National University of Ireland Galway School of Law's Legal and Political Theory Workshop, $8^{\text {th }}$ April 2016, p. 19. 
It helps restore a view that comparative law actually promotes the knowledge of what the law is. ${ }^{24}$ The law is a science between the is and the ought. ${ }^{25}$ It is composed of a set of rules followed or not, written or not. To a great extent it is situated in place and time and expresses and consolidates social interests, local attitudes and consolidations of social power. Nevertheless, it has a normative character as well. It inevitably concerns how human beings should interact. This element points towards the search for a normative validity that transcends its facticity (Habermas 1996, p. 31). This means that the effort to describe legal rules always leads to the adoption of a position on the validity of these rules from a normative perspective.

Habermas's analysis of the communicative nature of any analysis in the social sciences is relevant for the comparative law scholar (Habermas 1981, pp. 119121). Since the researcher studies rights, which are a subcategory of legal rules, interaction with the purpose and the importance of a right implies making a validity claim on the right that the researcher studies from a comparative perspective. It means that by the very fact of engaging in this comparative approach she engages in a communicative perspective where she is forced to test her own value commitments in reference to those of the various foreign legal orders that she is studying. This communicative dimension of the research provides the critical means to transcend her ex ante understandings and the schemata she projects in order to approach her topic. Also, the very object of the study, a comparison, provides for the possibility of a reflective self-control of the process of comparison. The confrontation of the social contexts can lead to reflecting on them in a way that transcends their particularity. The comparativist constitutes and hypostasizes the object of her study, the study of a legal order's attitude towards the protection of a right.

Gadamer's articulation of the hermeneutical circle (Gadamer 2004, pp. 272 seq.) is very helpful on this point. Ideally, the researcher will test her ex ante understanding of the dominant political ideas and interpretative schemata offered by others in reference to her new findings concerning the law in operation. A comparative law study offers an exemplary opportunity for what Gadamer calls the 'fusion of horizons' (Ibid.) between the author and the reader of the text. In Gadamer's thought both the reader and the author of the text are situated in a sociopolitical context that defines their approach to the text, but at the same time they both aspire to transcend their situation. This is what the metaphor of the 'horizon' denotes. The person who gazes at a 'horizon' has a perspective that is situated. At the same time, it is a horizon that she gazes at. She is trying to extend her gaze beyond what surrounds her, towards the limitless. She is a finite being aspiring to the limitless. This is what Kant also had in mind when he described the condition of humanity as positioned to scan the heavens (Kant 1991, p. 63). She is making an effort to transcend her circumstances to the extent that this is possible. The

24 Geoffrey Samuel underlines this need for an understanding of comparative law as an epistemology, as a scientific discourse that promotes the knowledge of what is the law.

25 As Jürgen Habermas (1996) has analysed extensively. 
difference between Kant and Gadamer lies in the extent of what they consider to be possible. Kant advocates for the use of a priori reason, while Gadamer sees reason itself as situated.

In the case of the comparativist the researcher is guided by her own assumptions defined by her own background. Nevertheless, comparative law is a communicative process. She is also guided by the expectation to discover the meaning of the new conception of the right that she studies that a foreign sociopolitical context assigns to it. In her effort to understand the validity of a right, she is inquiring into the validity of the rules themselves that she is studying. Rights are rules that regulate social interaction, and as such they are associated with validity claims. Reaching an understanding concerning this validity of a rule means that the researcher needs to discover the reasons that make possible an intersubjective recognition of the validity of the rule within a legal order. Strong collaboration and engagement with the way legal actors of the legal culture under study understand the need to protect a right is necessary and constitutive of this understanding. This presupposes an engagement with the political discourse of the legal system under consideration, which leads to blurring of the line of the practical and the theoretical. ${ }^{26}$ This discussion has the potential to transcend the validity for this context under study and to reflect in abstracto on the validity of the limitations of a right as such. This means that the very nature of her study incites her to reflect on reasons that would intersubjectively be valid in reference to the proper limitations of a right.

Habermas notes that a component of action coordination is inherent in the study of the social scientist. This is also present in the work of the comparatist. If the law is the science that par excellence aims at coordinating action, then the evaluation of validity of legal rules is, by definition, part of any effort to study action coordination. For cases of rights this means that the researcher is thus motivated to enlarge her definitions of and her understanding of validity claims in reference to the case she is studying. What kind of balancing of this right against other rights or collective considerations can be the best possible in one case or another? In this respect the comparatist will be led to offer a justification of her definitions and of the validity of the legal norms that she is studying. This can also be phrased as a moral obligation to the legal researcher to confront her own values to those she is studying.

An example can be helpful here. The study of headscarf bans in various European states presupposes an effort of the researcher to engage thoroughly with the socio-political context that makes these headscarf bans acceptable. ${ }^{27}$ What is the dominant philosophy on the role of the government that makes these limitations legitimate? The comparativist may be motivated by her own conception for or against the ban, and in this effort she may be prevented from actually engaging seriously with the ideas and the arguments on the other side. Nevertheless, as analysed earlier, a comparative enterprise is a communicative enter- 
prise; the researcher aims at establishing the importance and the validity of the regulation of a human right within the sociopolitical context of her study. In this respect there is a moral requirement for openness to the newness of the sociopolitical context under study. Understanding this sociopolitical context implies also understanding why in that context this legal rule is valid. The reasons for this validity may be different from the ones that the comparativist is projecting upon the object of her study. Her project thus implies making an implicit claim about its validity. Ideally, the researcher will corroborate her projections with scholars trained in the legal system she is studying. Furthermore, understanding the validity of these limitations does not necessarily mean accepting them. This claim can lead to a reflection on the validity of these limitations on the basis of an abstract theory on the legitimate role of the government in the regulation of headscarves in various social contexts such as schools and workplaces. The very study of this normative question will lead to a normative interrogation of the just limits of government intervention in regulating the wearing of headscarves in public places.

\section{Conclusion}

This article discussed three possible approaches a researcher can follow when she engages in comparative rights jurisprudence. The choice of these three methods, among many other possible ones, depends on the aims of the researcher. First, the researcher may aim to propose a theoretical framework for understanding differences or similarities in the protection of rights among various legal systems. This will mean engaging in a study that focuses on the social and political context that led to the elaboration of similarities or differences in the protection of rights. Elements of philosophy of history are intertwined with this approach to the extent that a reflection on the meaning of some historical events can make sense from a comparative point of view in reference to some broader philosophical ideas. In the area of rights this approach implies studying theories of government and seeing how jurists and other political actors made sense of them in order to respond to their sociopolitical needs. Second, a researcher may engage in a normative enterprise. This means she may be interested in reflecting critically upon differences and similarities in the regulation of rights in order to propose ways of regulating rights that are in conformity with principles of justice. This approach focuses on engaging in a philosophical analysis informed by the study of differences or similarities in the regulation of rights. The study of differences and similarities in the balancing of rights can provide stimuli for a philosophical reflection on the proper balancing of rights.

Third, a researcher may engage in an approach that combines elements from both these approaches. This means that she can engage first in understanding similarities or differences. Then this understanding may lead her to reflect critically on elaborating ways that can improve the state of the law. The study of the operation of the law in different contexts can provide insights into how they should be operating in order to protect rights better. This can provide guidance for future 
cases. According to this method, the comparative law means challenging the existing philosophical and sociopolitical frames that led to the elaboration of similarities and differences and reflecting on how the law can express principles of justice. This last approach is important in view of bringing about social change through the law. It is based on the idea that the researcher can reach a reflective equilibrium between how the law operates and how it should operate. All three approaches presuppose interdisciplinarity. The researcher needs to engage with research in social sciences, and this can help her understand the political and social purposes of legal rules. As such, all these approaches are extremely challenging for the researcher. They are challenging because of their ambitious interdisciplinary character.

Comparative law involves transcending the researcher's comfort zone as it implies studying legal rules in different social and political contexts from the researcher's own legal system. ${ }^{28}$ It also implies expanding the horizons of one's knowledge in the area of neighbouring disciplines, which can be extremely demanding. First, challenges concern the commensurability of the cases of rights under comparison. The researcher will need to ensure that the cases she is studying are comparable and that the comparison is worthwhile as it promotes the reflection on the justness of rules protecting rights. A second set of challenges relate to the difficulty in transcending the comparatist's subjectivity. The comparatist's formation in a context of meaning leads her to project meanings in her effort to make sense of the protection of rights in different legal contexts. These projections concern the formation of the research question, the choice of interpretative schemes and the conclusions of the researcher. Some prejudices, conscious and unconscious, will always condition her efforts to make sense of something new. The researcher has a moral obligation to check her prejudices to the extent that this is possible. She has a moral obligation to be open to the question she is studying. Overcoming one's limited perspective also can be facilitated through collaborations with scientists coming from other disciplinary backgrounds as well as with jurists coming from the foreign legal system that she is studying. Another set of challenges concern the difficulties that emerge in the very possibility to reflect critically about the law if our reflection is conditioned by our situation in a context of formation and social meanings. The nature of the activity the comparatist is engaged in can lead to transcending this challenge. Studying legal rules that protect rights always implies taking a position on the rights under consideration. The law is a normative discipline. A purely descriptive attitude towards it is impossible. Since this is the case the researcher in her effort to adopt a position will come up with criteria of justice that, to some extent, transcend her situation in a context of formation. The researcher will be led to think in abstracto about the just character of the rules protecting rights she is studying.

Comparative law offers the researcher the liberty to define her area of research, the goals of the research and the choice of methodology that is appropriate to her research. Nevertheless, liberty in the choice of methodology of comparative 
law does not mean anarchy. In the discourse of the legal science, which has as object a normative phenomenon, the law, justification is very important. Every legal interpreter of the law as a normative phenomenon is, by definition, involved in a process that leads him to present a justification of her choice of cases, methodology and validity of conclusions. She is also often forced to provide a justification that makes intersubjectively valid the substantive question that she studies. The liberty that the comparatist has in her choice of topic and methods can be the most creative element that can inspire a philosophical reflection on the very meaning and purpose in the area of rights jurisprudence. It can contribute to refining our evolving sense of justice in these issues. Every jurist that engages in legal interpretation is trying to reconstruct the meaning of a legal text. This is all the more the case for the legal comparatist. Even if to some extent despite the comparatist's efforts 'foreign laws' singularity remains unsaturable', ${ }^{29}$ the attempt to make sense of foreign legal cultures and to use this understanding in promoting a better vision about the law is always valuable. The researcher should be conscious of her limits. As William Ewald notes, comparative law is 'an essentially philosophical enterprise' ${ }^{30}$ aiming to uncover the reasons and justifications that underlie legal rules seeking answers to legal questions. As such, it is submitted to the inherent limits of philosophy itself. Nevertheless, the limits and challenges should not be a discouraging element but an encouraging one. The effort is all the more worthwhile as it can always incite a theoretical reflection towards the improvement of our legal ideas and, by extension, of our legal rules.

\section{References}

Adams, M. \& Griffiths, J. (2012) Against 'comparative method': explaining similarities and differences. In Adams M. and Bomhoff, J. (Eds.), Practice and theory in comparative law (pp. 279-301). Cambridge University Press.

Bomhoff, J. (2008). Balancing, the global and the local: judicial balancing as a problematic topic in comparative (constitutional) law. Hastings Int'l \& Comp. L. Rev., 31: 555-586.

Brand, O. (2006-2007). Conceptual comparisons: towards a coherent methodology of comparative legal studies. Brooklyn Journal of International Law, 32: 405-466.

Cotterrell, R. (2006). Comparative law and legal culture. In M. Reimann \& R. Zimmermann (Eds.), The Oxford Handbook of Comparative Law (pp. 709-737). Oxford University Press.

Cotterrell, R. (2016). Law, culture and society, legal ideas in the mirror of social theory. London: Routledge.

Dannemann, G. (2006). Comparative law: study of similarities or differences? In M. Reimann \& R. Zimmermann (Eds.), The Oxford handbook of comparative law (pp. 383-419). Oxford University Press.

Durkheim Émile, (Coser, L.A. trans.) (1984 [1893]). The division of labor in society. New York: The Free Press.

29 Pierre Legrand, 'Foreign Law: Understanding Understanding', 89.

30 William Ewald, 'Comparative Jurisprudence (I): What Was it Like to Try a Rat?', 1947. 
Ewald, W. (1995). Comparative jurisprudence (I): what was it like to try a rat? University of Pennsylvania Law Review, 143: 1889-2149.

Ewald, W. (1998). The jurisprudential approach to comparative law. The American Journal of Comparative Law, 46: 701-707.

Feyerabend, P. (1988 [1975]). Against method. London, New York: Verso.

Foucault, M. (1977). Discipline \& punish. (Alan Sheridan, trans.). New York: Vintage Books.

Foucault, M. (2010). The archaeology of knowledge. (A.M. Sheridan Smith, trans.). New York: Vintage Books.

Gadamer, H.G. (2004). Truth and method (J. Weinshemere \& D.G. Marshall trans., 2d 3d).

Geertz, C. (1993). Local knowledge: further essays in interpretive anthropology. London: Fontana.

Glendon, M.A., Carozza, P.G., \& Picker, C.B. (2007). Comparative legal traditions. (St.Paul Minessota, Thomseon/West).

Glenn, P. (2015). Against method. In Adams M. \& Heirbaut D. (Eds.), The method and culture of comparative law: essays in honour of Mark Van Hoecke (pp. 177-188). Oxford: Hart.

Grosswald Curran, V. (1998). Cultural immersion: difference and categories in U.S. comparative law. American Journal of Comparative Law, 46: 43-92.

Habermas, J. (1996). Between facts and norms, contributions to a discourse theory of law and democracy. (W. Regh trans.). MIT Press.

Habermas, J. (1981). Theory of communicative action, vol. I. Reason and the Rationalization of Society. (T. McCarthy trans.). Boston: Beacon Press.

Hart, H.L.A. (1961). The concept of law. Oxford: Calrendon Press.

Hegel, F. (1991). The philosophy of history. (J. Sibree trans.). Amherst: Prometheus Books.

Heidegger, M. (1962). Being and time. (J. Macquarrie \& E. Robinson trans.).

Hirschl, R. (2005). The question of case selection in comparative constitutional law. American Journal of Comparative Law, 53: 125-155.

Husa, J. (2014). Interdisciplinary comparative law - between Scylla and Charybdis? The Journal of Comparative Law, 9: 28-42.

Husa, J. (2015). Research designs of comparative law - methodology or heuristics? In Adams M. \& Heirbaut D. (Eds.), The method and culture of comparative law: essays in honour of Mark Van Hoecke (pp. 53-68).

Kant, I. (1991). On the common saying: it may be true in theory, but it does not apply in practice. In S. Reiss (Ed.) (H.B. Nisbet trans.). Political writings (p. 61-92). Cambridge University Press.

Leckey, F. (2017). Review of comparative law. Social \& Legal Studies, 26: 3-24.

Legrand, P. (1995). Comparative legal studies and commitment to theory. Modern Law Review, 58: 262-273.

Legrand, P. (1999). Fragments on law as culture. W.E.J. Tjeenk Willink, Schoordijk-Instituut.

Legrand, P. (2011). Foreign law: understanding understanding. Journal of Comparative Law, 6(2): 67-177.

Matagrin, A. (1910). La psychologie sociale de Gabriel Tarde. Paris: Félix Alcan.

Mautner, M. (2011). Three approaches to law and culture. Cornell Law Review, 96: 839-867.

McCrudden, C. (2017). What does it mean to compare, and what should it mean? In Comparing comparative law. Publications of the Swiss Institute of Comparative Law. Geneva/Zurich: Schulthess Editions Romandes 61-84.

Nelken, D. (2016). Comparative legal research and legal culture: facts, approaches, and values. The Annual Review of Law and Social Science, 12: 45-62.

Newcomb Hohfeld, W. (1964 [1913]). Some fundamental legal conceptions as applied in legal reasoning. New Haven: Yale University Press.

Palmer, V.V. (2005). From Lerotholi to Lando: some examples of comparative law methodology. The American Journal of Comparative Law, 47: 261-290. 
Paris, M-L. (2016). The comparative method in legal research: the art of justifying choices. In L. Cahillane \& J. Schweppe (Eds.), Legal research methods: principles and practicalities (pp. 39-55). Dublin: Clarus Press.

Rawls, J. (1973). A theory of justice. Oxford University Press.

Riles, A. (2006). Comparative law and socio-legal studies. M. Reimann \& R. Zimmermann (Eds.), The Oxford handbook of comparative law (pp. 775-813). Oxford University Press.

Samuel, G. (1998). Comparative law and jurisprudence. International and Comparative Law Quarterly, 47: 817-836.

Schwartz, P.M. (2013). The EU-U.S. privacy collision: a turn to institutions and procedures. Harv. L.R.. 126: 1966-2009.

Schwartz, P.M. \& Solove, D.J. (2014). Reconciling personal information in the United States and European Union. California Law Review, 102: 4, 877 - 916.

Smits, J. (2012). Rethinking methods in European private law. In Adams M. \& Bomhoff, J. (Eds.), Practice and theory in comparative law (pp. 170-185). Cambridge: Cambridge University Press.

Suk, J. (2007a). Discrimination at will: job security protections and equal employment opportunity in conflict. Stanford Law Review, 60: 73-113.

Suk, J. (2007b). From antidiscrimination to equality: stereotypes and the life cycle in the United States and Europe. The American Journal of Comparative Law, 60: 75-98.

Tarde, G. (1893). Les monades et la sociologie. Révue Internationale de Sociologie 157-175, 231-246.

Tourkochoriti, I. (2012). The burka ban: divergent approaches to freedom of religion in France and in the U.S.A. Wm. \& Mary Bill Rts. J., 20: 799-852.

Tourkochoriti, I. (2013). Revisiting Hosanna-Tabor v. E.E.O.C.: the road not taken. Tulsa Law Review, 49: 47-98.

Tourkochoriti, I. (2014a). Should hate speech be protected? Group defamation, party bans, holocaust denial and the divide between (France) Europe and the United States. Columbia Human Rights Law Review, 45: 552-622.

Tourkochoriti, I. (2014b). The transatlantic flow of data and the national security exception in the European data privacy regulation: in search for legal protection against surveillance. University of Pennsylvania Journal of International Law, 36: 459-524.

Tourkochoriti, I. (2015). 'Disparate impact' and 'indirect discrimination': assessing responses to systemic discrimination in the U.S. and the E.U. European Journal of Human Rights, 3: 297-324.

Tourkochoriti, I. (2017). Jenkins v. Kingsgate and the migration of the U.S. disparate impact doctrine in EU law. In F. Nicola \& B. Davies (Eds.), EU law stories (pp. 418-445). Cambridge University Press.

Tourkochoriti, I. Freedom of speech: a philosophical inquiry into the revolutionary roots of American and French legal thought. (manuscript).

Tushnet, M. (1998-1999). The possibilities of comparative constitutional law. Yale Law Journal, 108: 1225-1309.

Tushnet, M. (2017). The boundaries of comparative law. European Constitutional Law Review, 13: 13-22.

Valcke, C. (2004). Comparative law as comparative jurisprudence - the comparability of legal systems. American Journal of Comparative Law, 52: 713-740.

Valcke, C. (2012). Reflections on comparative law and methodology - getting inside contract law. In Adams M. \& Bomhoff, J. (Eds.), Practice and theory in comparative law (pp. 22-48). Cambridge: Cambridge University Press.

Valcke, C. \& Grellette, M. (2015). Three functions of function in comparative legal studies. In M. Adams \& D. Heirbaut (Eds.), The method and culture of comparative law: essays in honour of Mark Van Hoecke (pp. 99-111). Oxford: Hart. 
Van Hoecke, M. (2015). Methodology of comparative legal research. Law and Method, 15: 1-35.

Weber, M. (2003). The objectivity of knowledge in social science and social policy. In S. Whimster (Ed.), The essential Weber, a reader (p. 374). London and New York: Routledge.

Whitman, J. (2003). Harsh punishment and the widening divide between Europe - U.S.A. Oxford University Press.

Whitman, J.Q. (2004). The two western cultures of privacy: dignity versus liberty. The Yale Law Journal, 113: 1151-1221.

Whitman, J.Q. (2005). 'Human dignity' in Europe and the United States: the social foundations. In G. Nolte (Ed.), European and US constitutionalism (pp. 98 seq.). Strasbourg: Council of Europe Publishing, col. Science and technique of democracy.

Whitman, J.Q. (2000). Enforcing civility and respect: three societies. Yale Law Journal, 109: 1279-1398. 